\title{
Sex disparities in effects of cystic fibrosis-related diabetes on clinical outcomes: A matched study
}

\author{
Robert J Miller $\mathrm{BSc}^{1}$, Hugh D Tildesley MD², Pearce G Wilcox MD ${ }^{3}$, Hongbin Zhang MSc MEng ${ }^{4}$,
} Stuart $\mathrm{H}$ Kreisman $\mathrm{MD}^{5}$

\begin{abstract}
RJ Miller, HD Tildesley, PG Wilcox, H Zhang, SH Kreisman. Sex disparities in effects of cystic fibrosis-related diabetes on clinical outcomes: A matched study. Can Respir J 2008;15(6):291-294.
\end{abstract}

BACKGROUND: Cystic fibrosis-related diabetes (CFRD) is an increasingly prevalent comorbidity factor for patients with cystic fibrosis (CF). CFRD has been associated with an accelerated decline in clinical parameters and an increased mortality rate.

OBJECTIVES: To investigate the clinical impact of CFRD on pulmonary function and clinical status using a matched study design to further explore potential causality.

METHODS: Charts from the adult CF clinic at St Paul's Hospital (Vancouver, British Columbia) were retrospectively reviewed. Forty CFRD patients with and without fasting hyperglycemia were matched to CF patients with nondiabetic glucose tolerance based on sex, age and forced expiratory volume in $1 \mathrm{~s}\left(\mathrm{FEV}_{1}\right)$.

RESULTS: Sixteen of 40 CFRD patients (40\%) died compared with nine of 40 patient controls $(23 \%)(\mathrm{P}=0.13)$. CFRD patients were more likely to experience declines in $\mathrm{FEV}_{1}(\mathrm{P}<0.01)$, especially women $(\mathrm{P}<0.01)$. Patients with CFRD were not more likely to be hospitalized $(\mathrm{P}=0.39)$. Body mass index did not differ between groups.

CONCLUSIONS: Patients with CFRD had higher rates of FEV deterioration than nondiabetic patients with $\mathrm{CF}$, and showed a trend toward increased mortality. The present study suggests that CFRD has a significant clinical impact and should be carefully considered when evaluating the status of CF patients.

Key Words: Cystic fibrosis; Cystic fibrosis-related diabetes; Forced expiratory volume

Cystic fibrosis (CF) is the most common life-threatening Caucasian autosomal recessive disorder, with a prevalence of one in 2500 births (1). With improvements in treatment, the median life expectancy of CF patients has increased to 37.0 years (34.8 years in women) (2). CF-related diabetes (CFRD) affects one in four CF patients older than 20 years of age and is the leading comorbidity factor in patients with $\mathrm{CF}$ $(3,4)$. Because the median age of onset of CFRD is 20 years, and the life expectancy of the CF population continues to increase, the prevalence of CFRD is expected to grow $(3,5)$. The incidence of CFRD is also higher in women (6-8).

Forced expiratory volume in $1 \mathrm{~s}\left(\mathrm{FEV}_{1}\right)$ is strongly linked to clinical status (9). Pulmonary exacerbations lead to decreased
Les effets de la disparité des sexes sur les issues cliniques des patients atteints de diabète lié à la fibrose kystique : Une étude appariée

HISTORIQUE : Le diabète lié à la fibrose kystique (DLFK) est un facteur de comorbidité de plus en plus prévalent pour les patients atteints de fibrose kystique (FK). Le DLFK s'associe à une détérioration accélérée des paramètres cliniques et à une augmentation du taux de mortalité. OBJECTIFS : Explorer les répercussions cliniques du DLFK sur la fonction pulmonaire et l'état clinique au moyen d'une étude appariée pour évaluer la causalité potentielle de manière approfondie.

MÉTHODOLOGIE : Les dossiers de la clinique de FK pour adultes du St. Paul Hospital (de Vancouver, en Colombie-Britannique) ont fait l'objet d'une étude prospective. Quarante patients atteints de DLFK présentant ou non de l'hyperglycémie à jeun ont été appariés à des patients atteints de DLFK ayant une tolérance au glucose non diabétique d'après le sexe, l'âge et le volume expiratoire maximal par seconde (VEMS).

RÉSULTATS : Seize des 40 patients atteints de DLFK (40\%) sont décédés par rapport à neuf des 40 sujets témoins $(23 \%)(\mathrm{P}=0,13)$. Les patients atteints de DLFK étaient plus susceptibles de présenter une diminution du VEMS $(\mathrm{P}<0,01)$, notamment les femmes $(\mathrm{P}<0,01)$. Les patients atteints de DLFK ne couraient pas plus de risque d'être hospitalisés $(\mathrm{P}=0,39)$. L'indice de masse corporelle ne différait pas entre les groupes.

CONCLUSIONS : Les patients atteints d'un DLFK présentaient des taux de détérioration du VEMS plus élevés que les patients atteints de FK non diabétique et révélaient une tendance vers une mortalité accrue. Selon la présente étude, le DLFK a des répercussions cliniques importantes et devrait être soumis à un examen attentif au moment d'évaluer l'état des patients atteints de FK.

survivorship approximately equal to a $12 \%$ drop in $\mathrm{FEV}_{1}$ per admission. In some studies $(2,6,8,10)$, CFRD has been associated with increased mortality and a reduced median life expectancy, while in other studies (11-13) no difference was found. Similarly, some studies $(9,14)$ found that patients with CFRD experienced an accelerated decline in $\mathrm{FEV}_{1}$ two to four years before the diagnosis of diabetes, while another study (15) determined there was no clinical impact. Although the effect of CFRD remains unclear, the severity of glucose intolerance in CF patients correlates with the rate of pulmonary decline and lower pulmonary function variables $(3,4,6)$. However, the above data are primarily cross-sectional and may be consistent with CFRD being only a marker of more severe disease.

${ }^{1}$ Diabetes Research; ${ }^{2}$ Division of Endocrinology; ${ }^{3}$ Cystic Fibrosis Clinic, St Paul's Hospital; ${ }^{4}$ Department of Statistics, University of British Columbia;

${ }^{5}$ Division of Endocrinology, St Paul's Hospital, Vancouver, British Columbia

Correspondence: Dr Stuart H Kreisman, St Paul's Hospital, 301-1160 Burrard Street, Vancouver, British Columbia V6Z 2E8.

Telephone 604-681-3501, fax 604-681-4508, e-mail stuarthk@telus.net 
TABLE 1

Medical treatments and body mass index (BMI) at time of matching

\begin{tabular}{lccc}
\hline Treatment & $\begin{array}{c}\text { Diabetic patients } \\
(\mathbf{n = 4 0 )}\end{array}$ & $\begin{array}{c}\text { Control patients } \\
(\mathbf{n}=\mathbf{4 0 )}\end{array}$ & $\mathbf{P}$ \\
\hline Insulin, $\mathrm{n}(\%)$ & $24(60)$ & $\mathrm{N} / \mathrm{A}$ & $\mathrm{N} / \mathrm{A}$ \\
Metformin and insulin, $\mathrm{n}(\%)$ & $5(13)$ & $\mathrm{N} / \mathrm{A}$ & $\mathrm{N} / \mathrm{A}$ \\
Diet, $\mathrm{n}(\%)$ & $6(15)$ & $\mathrm{N} / \mathrm{A}$ & $\mathrm{N} / \mathrm{A}$ \\
Sulfonylureas, $\mathrm{n}(\%)$ & $5(13)$ & $\mathrm{N} / \mathrm{A}$ & $\mathrm{N} / \mathrm{A}$ \\
Prednisone therapy, $\mathrm{n}(\%)$ & $11(28)$ & $0(0)$ & $<0.01$ \\
BMl, kg/m & 20.69 & 21.05 & $\mathrm{~N} / \mathrm{A}$ \\
\hline
\end{tabular}

N/A Not applicable

Therefore, to more clearly demonstrate the role of CFRD as an independent causative factor for clinical decline, we matched CFRD patients with nondiabetic CF patients to isolate its effect, then assessed their clinical outcomes over the ensuing years.

\section{METHODS}

Subjects were identified by a review of 322 patients who attended the adult CF clinic at St Paul's Hospital (Vancouver, British Columbia) between 1977 and 2005. Patients were classified as CFRD with fasting hyperglycemia (FH), CFRD without FH, impaired glucose tolerance (IGT) or normal glucose tolerance based on existing blood work. An oral glucose tolerance test result of greater than $11.0 \mathrm{mmol} / \mathrm{L}$ indicated CFRD, while a result between $7.8 \mathrm{mmol} / \mathrm{L}$ and $11.0 \mathrm{mmol} / \mathrm{L}$ defined IGT. A fasting blood glucose value of higher than $7.0 \mathrm{mmol} / \mathrm{L}$ indicated CFRD with FH, while a fasting blood glucose result of $7.0 \mathrm{mmol} / \mathrm{L}$ or lower in patients with CFRD indicated CFRD without FH.

In total, 78 of 322 patients (24.2\%) had documented altered glucose tolerance. Of these patients, four were lost to follow-up, four were transferred to another clinic and two had no recorded pulmonary data before death. Of the remaining 68 patients, $14(20.6 \%)$ were eventually diagnosed with IGT and were included in the matching group. Two patients with IGT were used in matching: one was diagnosed with CFRD after the death of her matched patient and the other was diagnosed two years after matching. Five transplant patients and nine patients who had been colonized with Burkholderia cepacia were excluded.

Of patients with normal glucose tolerance, two had no pulmonary data recorded before death, 35 were lost to follow-up and 34 were transferred to a different clinic. Of the remaining patients, $12(7 \%)$ had been colonized with B cepacia and were excluded. The remaining 161 patients together with 14 IGT patients became the matching group.

Forty patients (15 male [38\%]), classified as CFRD with FH (34 of 40 patients [85\%]) and CFRD without FH (six of 40 patients [15\%]), were matched to controls. Cases were matched two years before diagnosis to account for possible effects of the prediabetic phase. Pairs were matched exactly by sex and age, then to the closest $\mathrm{FEV}_{1}$ match. There were no cases in which multiple potential matches had equally close $\mathrm{FEV}_{1}$ values. Only controls born within four years of the CFRD patient in question were considered for matching to eliminate effects from differing therapies over time. For five patients, pulmonary data were not available two years before diagnosis, and matching occurred in the year before diagnosis in three patients and the year of diagnosis in two patients. Patients were identified using a study code identification to minimize possible bias in matching.

The first spirometry measurement in each year was used. Body mass index (BMI) was calculated from the first height and weight measurements in each year.

A Cox proportional hazard model corrected for steroid use was used to determine significance in mortality. $\mathrm{FEV}_{1}$ and BMI were analyzed using a generalized estimate equation corrected for steroid use. A decrease from $0 \%$ to $9 \%$, from $10 \%$ to $19 \%$, and greater than $20 \%$ were used as ordinal categories. Patients who died were considered to be in the highest ordinal group for FEV and forced vital capacity (FVC). Male and female interactions were added to the generalized estimate equation model to analyze sex effects. Admissions were defined as a hospitalization for any cause. The rate of admissions was analyzed using a generalized estimate equation for the prematching period, the matching to diagnosis period and the postdiagnosis period, representing the time points, with none, one, and more than one admission comprising the ordinal categories. Glycosylated hemoglobin $\mathrm{A} 1 \mathrm{c}$ (A1C) values were compared in CFRD patients using a repeated measures ANOVA. Analyses were performed using SAS 9.1 (SAS Institute Inc, USA).

Ethics approval was obtained from the University of British Columbia/Providence Health Care Research Ethics Board.

\section{RESULTS}

The mean age at diagnosis of CFRD was 24.5 years (men, 25.4 years; women, 23.8 years). Sixteen of 40 patients ( $40 \%$ ) with CFRD (five male and 11 female) and nine of 40 controls (23\%) (four male and five female) died (hazard ratio=1.918; $\mathrm{P}=0.1303$ ) with median survival of 10.4 years and 16.14 years after matching, respectively.

Diabetic (23\%) therapy, prednisone therapy and BMI at time of matching are presented in Table 1. Eight CFRD patients were on pulses of prednisone, while three were on longer courses. Two patients had allergic bronchopulmonary aspergillosus, one on a pulse and one on a long course of prednisone. Only four cases were taking prednisone between the time of matching and diagnosis of CFRD; the others were prescribed prednisone after CFRD diagnosis. BMI remained unchanged in both groups throughout the study period, and there was no significant difference in BMI between groups ( $\mathrm{OR}=0.889,95 \%$ CI 0.451 to $1.752 ; \mathrm{P}=0.733$ ).

There was no significant difference in $\mathrm{FEV}_{1}$ between groups in the years before matching. However, CFRD patients were more likely to experience decreases in $\mathrm{FEV}_{1}$ between annual measurements ( $\mathrm{OR}=2.947,95 \%$ CI 1.516 to $5.727 ; \mathrm{P}=0.0014$ ). Mean $\mathrm{FEV}_{1}$ for patients with CFRD from the time of matching to four years later were $65.8 \%, 57.4 \%, 53.0 \%, 49.3 \%$ and $52.6 \%$ compared with $66.3 \%, 62.2 \%, 64.0 \%, 62.3 \%$ and $63.7 \%$ in controls (Figure 1).

Male CFRD patients were not more likely to experience decreases in $\mathrm{FEV}_{1}$ between annual measurements $(\mathrm{OR}=1.371$, 95\% CI 0.468 to 4.014; $\mathrm{P}=0.565)$. However, female CFRD patients were more likely to experience decreases in $\mathrm{FEV}_{1}$ between annual measurements $(\mathrm{OR}=4.409,95 \%$ CI 1.84 to $10.562 ; \mathrm{P}=0.0009$ ). From the time of matching to four years later, female patients had mean $\mathrm{FEV}_{1}$ values of $70.3 \%, 62.3 \%$, $56.4 \%, 53.4 \%$ and $52.7 \%$ compared with $69.4 \%$, 66.8\%, $68.3 \%, 69.8 \%$ and $67.5 \%$ in controls (Figure 2). Results for 


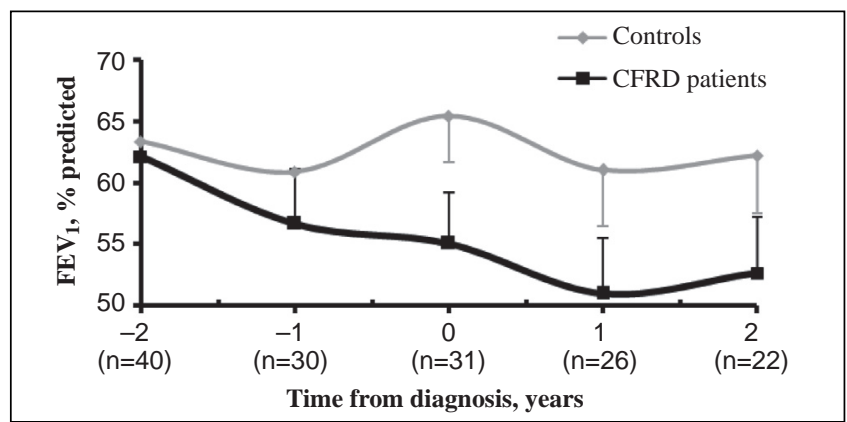

Figure 1) Mean forced expiratory volume in $1 \mathrm{~s}\left(\mathrm{FEV}_{1}\right)$ over time with standard error. CFRD Cystic fibrosis-related diabetes

FVC over time revealed the same pattern and sex disparities (data not shown).

The mean number of hospitalizations per year leading up to matching, from matching to diagnosis and after diagnosis was $0.49,1.15$ and 1.17 for cases and $0.69,0.47$ and 0.50 for controls, respectively. However, after correcting for steroid use, there was no significant difference in the odds of being admitted $(\mathrm{OR}=1.472,95 \% \mathrm{CI} 0.612$ to $3.54 ; \mathrm{P}=0.3873)$ (Figure 3$)$. The number of days in the hospital was also not significantly different between groups.

From matching to four years later, the mean A1C value for patients with CFRD was $6.2 \%, 7.9 \%, 7.9 \%, 8.0 \%$ and $7.3 \%$ $(\mathrm{P}=0.014)$. Control values during the same period were $5.6 \%$, $5.2 \%, 5.6 \%, 5.5 \%$ and $5.4 \%$. Mean A1C was not different between older or more recent calendar years. There was also no significant difference in $\mathrm{A} 1 \mathrm{C}$ values between male and female patients.

\section{DISCUSSION}

CFRD has been linked to worsened prognosis; therefore, further studying of its effect on patient outcome is clearly clinically relevant. Previous studies have been cross-sectional and thus incapable of determining causality. Many studies $(2,4,6)$ are compilations of registry data, while others used clinic data $(11,13,16)$. Liou et al $(10)$ used registry data to create a survivorship model that they validated with the remaining registry data. All of the above studies were cross-sectional and therefore potentially confounded by the possibility that CFRD only affects sicker patients. In our study, we addressed this limitation by matching individuals by disease severity.

We found that patients with CFRD were more likely to experience a decline in $\mathrm{FEV}_{1}$ and $\mathrm{FVC}$ in the years following matching. A1C values remained elevated in the years following diagnosis, suggesting that insufficient treatment or patient noncompliance may have contributed to this finding. Mortality was also nonsignificantly higher in patients with CFRD than the controls in our study. Although the difference did not attain statistical significance in this small sample, the mortality rate has been reported elsewhere to be higher in patients with CFRD (2), while another study (12) reported no difference. However, the latter study was cross-sectional and had a low median survival age, which would obscure the effect of CFRD on mortality. Matching also allowed us to account for patients who died before reaching the median age of onset of CFRD. The importance of matching in assessing CFRD mortality is illustrated by an earlier unmatched assessment of our own clinic's outcomes, which showed a higher median survival age in CFRD cases.

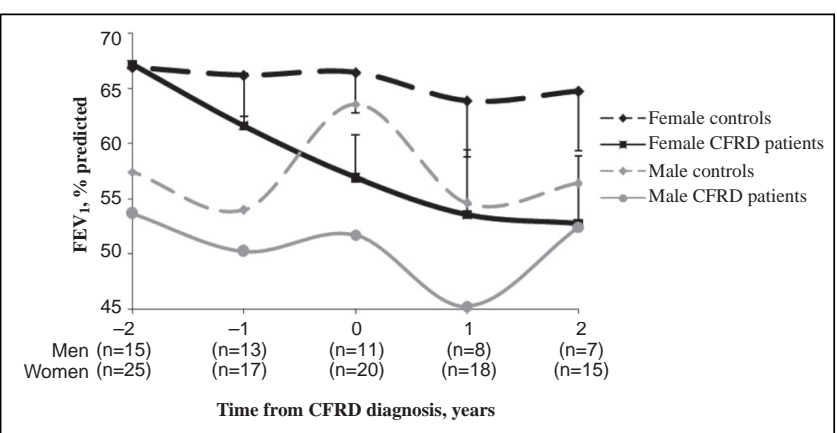

Figure 2) Forced expiratory volume in $1 \mathrm{~s}\left(\mathrm{FEV}_{1}\right)$ over time according to sex, with standard error. CFRD Cystic fibrosis-related diabetes

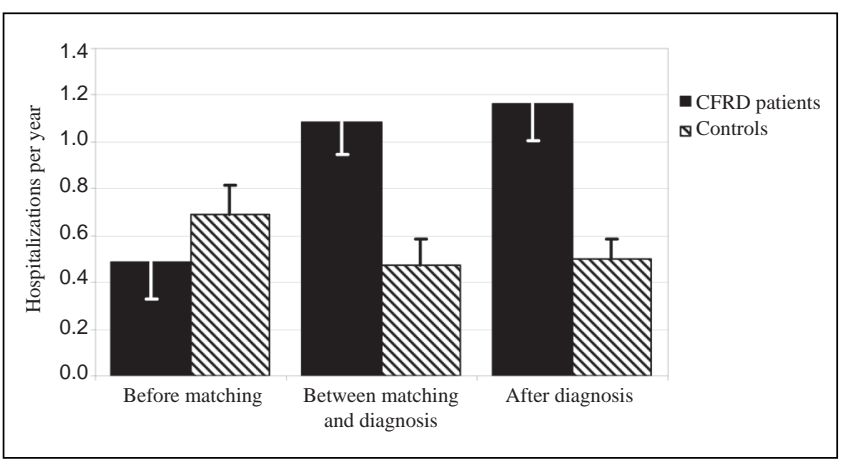

Figure 3) Mean number of hospitalizations per year with standard error. CFRD Cystic fibrosis-related diabetes

There is evidence to suggest that pulmonary function is affected even in non-CF patients with diabetes, which may help to explain our findings. Glycosylation of collagen tissue in the lungs reduces elasticity and total capacity $(17,18)$. Dehydration and protein catabolism lead to fatigue and weakness, potentially decreasing pulmonary performance $(19,20)$. Also, microangiopathy decreases gas exchange by reducing capillary blood volume $(21,22)$. Reduction in pulmonary parameters has previously been shown to lead to an increase in all-cause mortality in patients with type 2 diabetes (23). Additionally, patients with diabetes have an impaired ability to fight some infections, have increased rates of colonization and have decreased survivorship (6,24). Certainly these issues would be magnified in the CF cohort and could understandably lead to the serious clinical effects seen.

We found no difference in BMI between groups. However, previous studies $(4,6)$ found that BMI was lower in CFRD patients older than 15 years of age. The difference in our results could be caused by the anabolic effect of insulin therapy; however, $\mathrm{A} 1 \mathrm{C}$ values remained elevated suggesting that the effect of insulin therapy was limited and another factor may be responsible. The difference could also be caused by more aggressive nutritional therapy. Alternatively, matching patients may have removed the difference between groups because CFRD patients were likely sicker than controls in those studies. It is also possible that our study size was not large enough to distinguish the difference found in previous studies. We also found that patients with CFRD were not more likely to be hospitalized after correcting for steroid treatment.

The decline in pulmonary parameters and trend toward increased mortality was only significant in female patients. 
While the lack of effect in males could have been, in part, due to the lower number of male patients, previous studies also found a difference only in female patients for FEV (25) and mortality (16). This finding suggests that female CF patients are more severely affected by CFRD, which could account for a portion of the sex gap in overall CF survival. Some authors have proposed that the effects of gonadal steroids on pulmonary status may be responsible (16).

Our study has several limitations. Because we relied on existing data to classify patients, some CFRD patients may have been missed or misclassified as controls. Two patients later diagnosed with IGT were knowingly used in the control group; therefore, dysglycemia contaminated the control group to at least a small degree. Patients with B cepacia were excluded; the prevalence of which was higher in CFRD patients. Five patients could not be matched two years before diagnosis, thus failing to take into account the prediabetic decline. However, all of the above limitations would have only reduced the differences seen between groups. Patients with CFRD also had a higher rate of corticosteroid use at baseline, suggesting that they may have been in worse clinical condition in spite of similar $\mathrm{FEV}_{1}$ values at matchup. However, $\mathrm{FEV}_{1}$ appeared similar in the years leading to matchup (data not shown), suggesting that both groups were trending downward at a similar rate, and steroid use was included as a correcting factor. Accordingly, we believe that our results were not substantially affected by any of the above limitations

\section{CONCLUSIONS}

We have shown that patients with CFRD have accelerated worsening of pulmonary parameters, and a trend toward increased mortality rates compared with equivalent $\mathrm{CF}$ controls with normal glycemic tolerance. Female patients seemed to be more severely affected. The difference in clinical outcome observed suggests that early identification of CFRD should be a priority for any CF care centre.

ACKNOWLEDGEMENTS: Special thanks to Janet Hopkins, who shared her expertise and facilitated access to the data at the adult CF clinic of St Paul's Hospital. The authors also thank the Endocrine Research Society and St Paul's Hospital Foundation for their support.

\section{REFERENCES}

1. Brennan AL, Geddes DM, Gyi KM, Baker EH. Clinical importance of cystic fibrosis-related diabetes. J Cyst Fibros 2004;3:209-22.

2. Canadian Cystic Fibrosis Foundation. Report of the Canadian Patient Data Registry. Toronto: Canadian Cystic Fibrosis Foundation, 2002.

3. Lanng S, Thorsteinsson B, Lund-Andersen C, Nerup J, Schiøtz PO, Koch C. Diabetes mellitus in Danish cystic fibrosis patients: Prevalence and late diabetic complications. Acta Paediatr 1994;83:72-7.

4. Koch C, Rainisio M, Madessani U, et al. Presence of cystic fibrosisrelated diabetes mellitus is tightly linked to poor lung function in patients with cystic fibrosis: Data from the European Epidemiologic Registry of Cystic Fibrosis. Pediatr Pulmonol 2001;32:343-50.

5. Mackie AD, Thornton SJ, Edenborough FP. Cystic fibrosis-related diabetes. Diabet Med 2003;20:425-36.

6. Marshall BC, Butler SM, Stoddard M, Moran AM, Liou TG, Morgan WJ. Epidemiology of cystic fibrosis-related diabetes. J Pediatr 2005; 146:681-7.

7. FitzSimmons SC. The changing epidemiology of cystic fibrosis. J Pediatr 1993;122:1-9.

8. Finkelstein SM, Wielinski CL, Elliott GR, et al. Diabetes mellitus associated with cystic fibrosis. J Pediatr 1988;112:373-7.

9. Milla CE, Warwick WJ, Moran A. Trends in pulmonary function in patients with cystic fibrosis correlate with the degree of glucose intolerance at baseline. Am J Respir Crit Care Med 2000;162:891-5.

10. Liou TG, Adler FR, Fitzsimmons SC, Cahill BC, Hibbs JR, Marshall BC. Predictive 5-year survivorship model of cystic fibrosis. Am J Epidemiol 2001;153:345-52.

11. Reisman J, Corey M, Canny G, Levison H. Diabetes mellitus in patients with cystic fibrosis: Effect on survival. Pediatrics 1990;86:374-7.

12. Thornsteinsson B, Lanng S, Nerup J, Koch C. Epidemiology of glucose intolerance in cystic fibrosis. Diabetes 1991;40:320A.

13. Rodman HM, Doershuk CF, Roland JM. The interaction of 2 diseases: Diabetes mellitus and cystic fibrosis. Medicine (Baltimore) 1986;65:389-97.

14. Rolon MA, Benali K, Munck A, et al. Cystic fibrosis-related diabetes mellitus: Clinical impact of prediabetes and effects of insulin therapy. Acta Paediatr 2001;90:860-7.

15. Cucinotta D, Arrigo T, De Luca F, et al. Metabolic and clinical events preceding diabetes mellitus onset in cystic fibrosis. Eur J Endocrinol 1996;134:731-6.

16. Milla C, Billings J, Moran A. Diabetes is associated with dramatically decreased survival in female but not male subjects with cystic fibrosis. Diabetes Care 2005;28:2141-4.

17. Schnider SL, Kohn RR. Glucosylation of human collagen in aging and diabetes mellitus. J Clin Invest 1980;66:1179-81.

18. Lange P, Groth S, Kastrup J, et al. Diabetes mellitus, plasma glucose and lung function in a cross-sectional population study. Eur Respir J 1989;2:14-9.

19. Ferry M. Strategies for ensuring good hydration in the elderly. Nutr Rev 2005;63:S22-9.

20. Weekers F, Giulietti AP, Michalaki M, et al. Metabolic, endocrine, and immune effects of stress hyperglycemia in a rabbit model of prolonged critical illness. Endocrinology 2003;144:5329-38.

21. Sandler M. Is the lung a 'target organ' in diabetes mellitus? Arch Intern Med 1990;150:1385-8.

22. Sinha S, Guleria R, Misra A, Pandey RM, Yadav R, Tiwari S. Pulmonary functions in patients with type 2 diabetes mellitus \& correlation with anthropometry $\&$ microvascular complications. Indian J Med Res 2004;119:66-71.

23. Davis WA, Knuiman M, Kendall P, Grange V, Davis TM. Glycemic exposure is associated with reduced pulmonary function in type 2 diabetes: The Fremantle Diabetes Study. Diabetes Care 2004;27:752-7.

24. Joshi N, Caputo GM, Weitekamp MR, Karchmer AW. Infections in patients with diabetes mellitus. N Engl J Med 1999;341:1906-12.

25. Sims EJ, Green MW, Mehta A. Decreased lung function in female but not male subjects with established cystic fibrosis-related diabetes. Diabetes Care 2005;28:1581-7. 


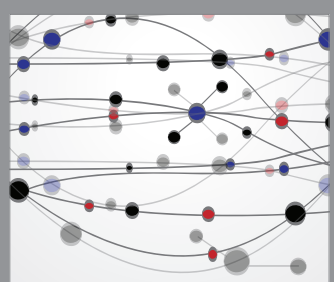

The Scientific World Journal
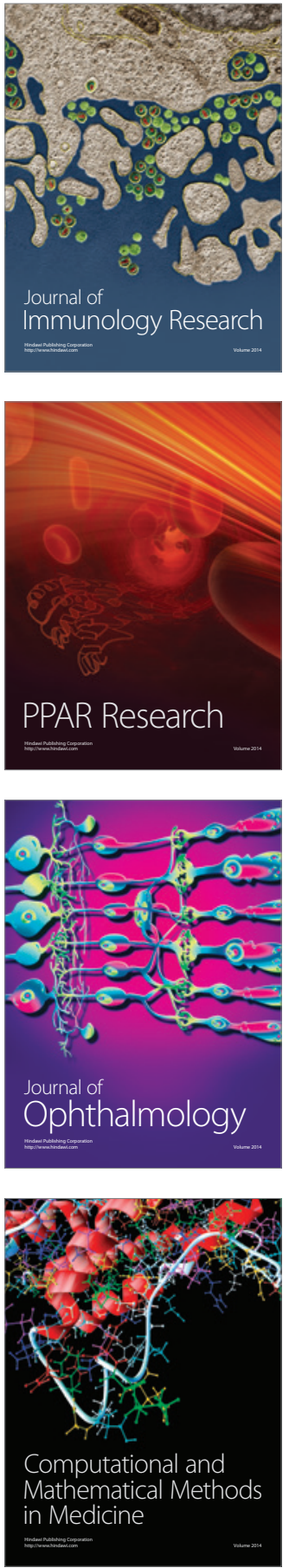

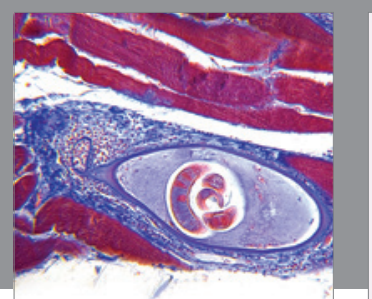

Gastroenterology Research and Practice

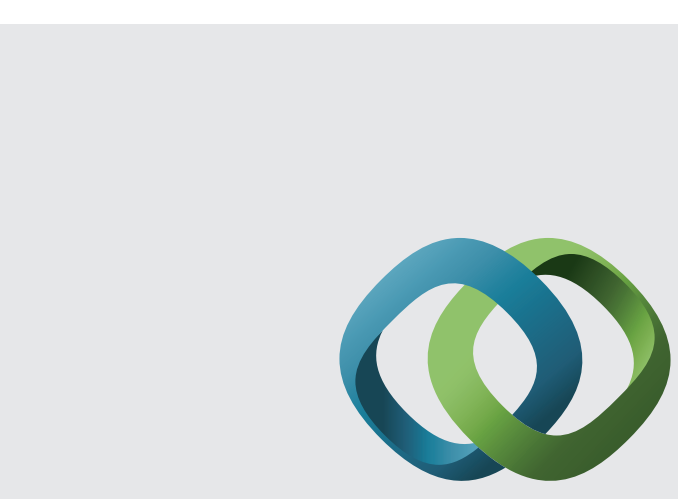

\section{Hindawi}

Submit your manuscripts at

http://www.hindawi.com
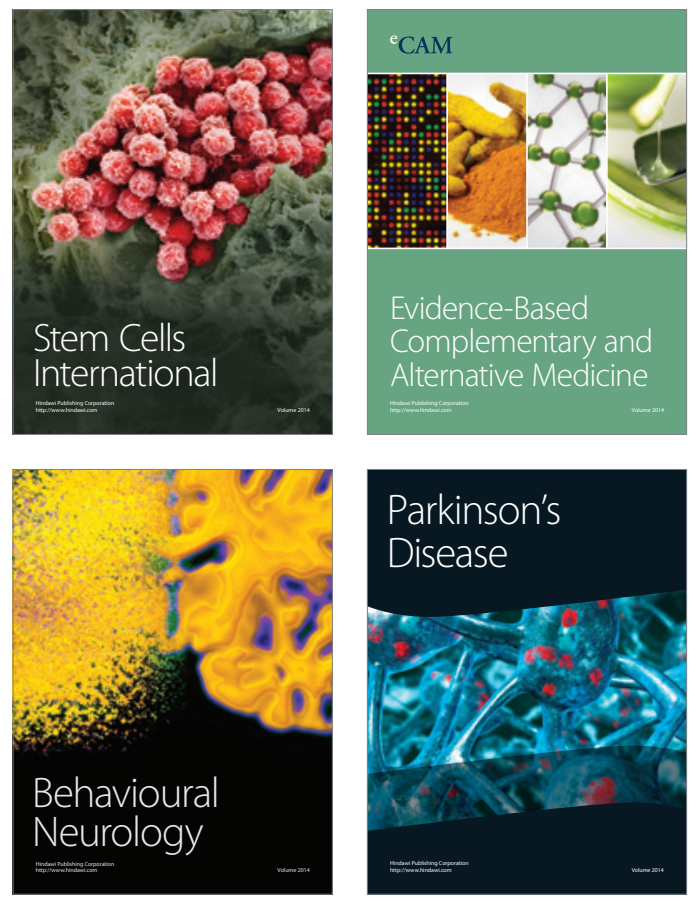
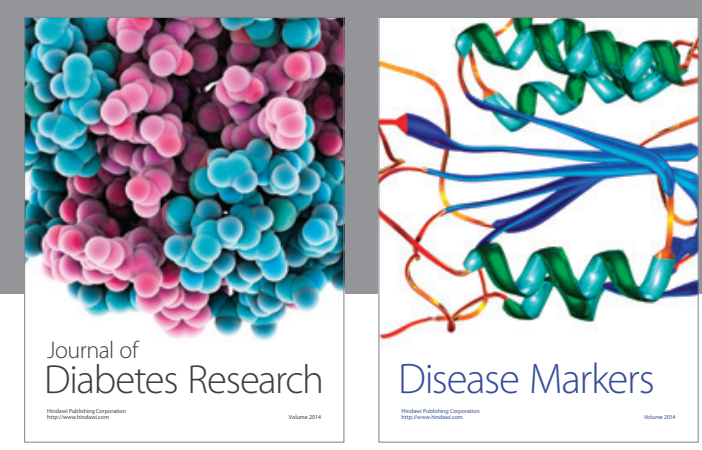

Disease Markers
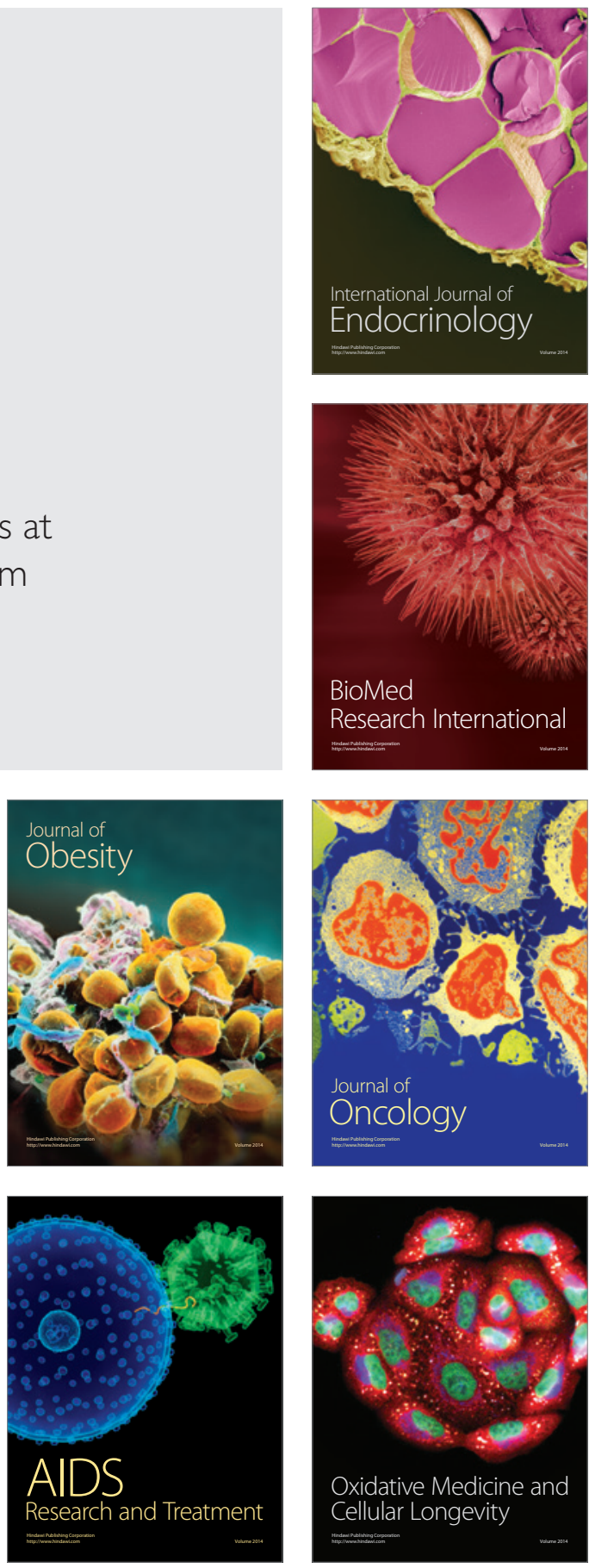